\title{
Satisfaction Levels, Opinions, and Experiences of Asian Faculty on Campus: Does Citizenship Status Make A Difference?
}

\author{
Patricia G. Boyer \\ University of Missouri-St. Louis \\ 269 Marillac Hall St. Louis, MO 63121 (314)516-7396 \\ Shawn Woodhouse \\ University of Missouri \\ 269 Marillac Hall St. Louis, MO 63121 \\ Pi-Chi Han \\ National Kaohsiung Normal University \\ No.116, Heping 1st Rd., Lingya District \\ Kaohsiung, Taiwan 80201
}

\begin{abstract}
The increasing complexity and diversity of U.S. society has enhanced the challenge of accommodating the needs of immigrants. University campuses in the United States are also becoming increasingly diverse, yet we cannot assume that diversity of numbers equates with acceptance of and respect for differences. The purpose of this study was to determine if there are differences in the perceptions of the campus and academic environment of Asian faculty employed in U.S. higher education institutions. There were three groups of Asian faculty members studied (1) U.S. citizens; (2) citizens, foreign born; and (3) non citizens using NSOPF:99 self-reported database. The theoretical framework utilized for this study is Herzberg's work on hygiene theory, which explains the differences between employee satisfaction and dissatisfaction, as well as workplace factors that cause satisfaction or dissatisfaction. Several Multiple Analysis of Variance (MANOVA) were conducted to determine if there were statistically significant differences among the three groups of faculty focusing on 17 satisfaction and 12 opinion variables. The overall findings of the study revealed that Asian faculty members were both "somewhat dissatisfied" and "disagreed" with the majority of opinion variables related to the campus and academic environment. The study concludes with implications for administrators who will support Asian faculty members employed at higher education institutions.
\end{abstract}

"Every human who speaks a language has an accent, and every human who listens to others talk perceives an accent” (Kavas \& Kavas, 2008, College Student Journal, p. 879).

\section{INTRODUCTION}

Globalization demands are transforming the boundaries of the world, resulting in fundamental implications for the mobility of people across geographical boundaries (Baruch, Budhwar, \& Khatri, 2007). The increase in globalization has caused dramatic shifts and rapid changes in the U.S. population and transformed the demographics of educational institutions, society and the workplace.

The foreign-born population has been a crucial element in the development of the history of the United States with immigrant labor being the underpinning of this country's economic success (Lin, Pearce \& Wang, 2009, p. 717). The U.S. continues to attract large number of foreign-born people. In fact, in 2010, fourteen million foreign-born people lived in the U.S. (ACS as cited by Walters and Trevelyan, 2011, p. 1), with $40 \%$ of the foreign-born population coming from Asia (China \& India) and another 40\% coming from Latin America and the Caribbean 
(p.2). The increasing complexity and diversity of U.S. society has enhanced the challenge of accommodating the needs of immigrants.

The U.S. Census Bureau (2007) released a report in the publication American Community which indicated that Asians represented 4.7 percent of the U.S. household population. The increase represented a continuation of this population's rapid growth since 1970, when it numbered about 800,000. The total percentage of Asian/Pacific Islanders more than tripled in the 1970s, and subsequently doubled in the 1980s (U.S. Census Bureau). According to Lee and Kumashiro (2005), "The Asian American and Pacific Islander [AAPIs] category is very diverse with over 50 ethnic groups, 100 language groups, and numerous religious groups. Some AAPIs are multiple-generation Americans, some are from immigrant families, and some are refugees" (p. 12).

\section{Purpose of the Study}

A close analysis of university campuses in the United States confirm they are becoming increasingly diverse, yet we cannot assume that racial diversity represented in quantitative terms equates with acceptance of and respect for differences. For instance, the National Center for Education Statistics (NCES, 2011) revealed that Asian Americans comprise approximately nine percent of higher education faculty and lag behind their White counterparts (79\%) in rank as the second largest. Unfortunately, although our campuses are ethnically and racially diverse, intolerance and exclusion are too often the experience of ethnic and racial minority faculty members (Johnsrud \& Sadao, 1998; Milem, Chang \& Antonio, 2005), staff, and students. A number of research studies have been conducted regarding faculty productivity (e.g. Jung, 2012; Herzog, 2010; Mamiseishvili \& Rosser, 2009; Sabharwal \& Corley, 2009; Tack \& Patitu, 1992) and productivity by gender (e.g. Sax, Hagedorn, Arredondo, \& DiCrisi, 2009; Hagedorn, 2001). A limited amount of research has been conducted regarding satisfaction levels, opinions, and experiences of Asian faculty, especially those who are temporary residents of the United States and foreign-born citizens. Specifically, the purpose of this study is an attempt to better understand Asian faculty members based on citizenship status (U.S. born, foreign-born, non-citizen) and to evaluate similarities and differences in their satisfaction levels, opinions, and experiences on the college campus. Spector as cited by Daly and Dee (2006) define job satisfaction as "an affective response that an organizational member has toward his or her particular job, and results from the employee's comparison of actual outcomes with those that are expected" (p. 785).

\section{Literature Review}

According to Open Doors, a publication released by the Institute of International Education (IIE, 2009), 113,494 international scholars were teaching or conducting research on U.S. campuses, an increase of $7 \%$ from the previous year. Open Doors indicated that the top four leading places of origin of international scholars, China, India, South Korea, and Japan, respectively, comprised $46.8 \%$ of the entire pool. Madhavan (2001) argues that in postsecondary institutions, the need for highly qualified scholars has grown dramatically. Asian international scholars in science and engineering ranked very high on the list of international scholars and many of them have held non-immigration visas (see Freeman, 2006). Many universities and colleges have recruited highly competent faculty from Asian countries such as China and India to fill these positions (Galladay, 1989; Madhavan, 2001; Freeman, 2006) and address a void. Although the pursuit of an academic career has been a vital path for Asian foreign-born scholars in the U.S. (Pang \& Appleton, 2004) and has nstigated a growing presence of these faculty on college campuses, they have been largely ignored in higher education literature (Mamiseishvili \& Rosser, 2009). 
Ali (2009) asserts that a higher proportion of Asian/Pacific Islander faculty members have been recognized as a high-achieving group who is committed to a high level of responsibility, and they performed better than other races in his study. A "typical" minority profile for Asian Americans has emerged in many studies (Fujimoto, 1996; Lee, 2006; Ng, Lee, \& Pak, 2007; Lei, 1998; Suzuki, 2002; Lee \& Kumashiro, 2005). Specifically, Ng, Lee, and Pak assert that Asian Americans have been persistently considered as the perpetual foreigners (Tuan, 1998) and model minority stereotypes in the mainstream culture of the U.S.

"Asian American faculty... have been stereotyped to be passive and hard-working but they are incapable of leadership" (Ng, et al., p. 118). They have also been described as "the silent group" in predominantly White colleges and universities (Stanley, 2006) and the definition of "white" was expanded to include Asians (Omi, 2008). Saigo (2008) questions the fact that although Asians are represented in the STEM fields, they do not hold positions of leadership in higher education institutions or in professional organizations. Lee (2002) proclaims that Asian faculty members have experienced many problems such as the glass ceiling effect. Moreover, many research studies consistently report that Asian foreign-born faculty have to work harder than their American colleagues to achieve their goals (Sieu, 1990; Madhavan, 2001).

In a recent study, Stanley (2006) contends that the feelings of isolation and low satisfaction regarding professional accomplishments have affected the lives of faculty of color including Asian American faculty. A review of the literature revealed that faculty of color experience higher levels of work stress than their White counterparts (Bronstein, 1993; Ruffins, 1997; Smith \& Witt, 1996; Stanley, 2006); the fear of not achieving tenure and promotion (Turner, 2002); and they struggled with lower tenure rates (Hune \& Chan, 1997). Therefore, in order to be successful in academe, faculty of color have to work twice as hard to be treated as equal (Laden \& Hagedorn, 2000). Jackson (2004) stated that the problem experienced by faculty of color and some women include feelings of being "discouraged, less supported, and perceived the tenure process to be less fair, than their white male colleagues" (pp. 179-180).

Several problems inundate the literature regarding Asian faculty, especially those who are not permanent citizens, such as the topic of limited English proficiency and its effect in the academy and their daily life activities. Another problem for temporary citizens is the experience of a certain degree of culture shock (Bockner, 2003), stress, and sociocultural disruption. Kavas \& Kavas (2008) contend that "cultural differences are sometimes misconstrued as a language barrier; therefore, method and styles of teaching may negatively affect communication in the classroom" (p. 882). Similar to Asian American faculty, Asian foreign-born faculty also present some unique problems related to their cultural adaptation and assimilation to the American culture (Madhavan, 2001). Many of them reported a feeling of being outsiders and a concern with having communication issues and misunderstandings, and experiencing discrimination (Madhavan), which can lead to job dissatisfaction.

Research on Asian Americans and similar research topics have been marginalized (Chan, 2005; Nakanishi, 1993). There is limited literature regarding Asian faculty, specifically research that pertains to job satisfaction and opinions among this faculty population, thus the purpose and importance of this research.

\section{THEORETICAL FRAMEWORK}

Faculty perceptions of job satisfaction in the work environment is the focus of this study, therefore it is important to discuss the concept of motivation and its implications regarding faculty job satisfaction. Motivation is a "major individual level variable" (Kreitner \& Kinicki, as cited in Zhang \& von Dran, 2000, p. 1255) that is indicative of productivity and job satisfaction. Kreitner and Kinicki explain that motivation is an individual level variable because "job 
satisfaction is defined as an affective or emotional response to one's job" (p. 1255) that is predicated upon intrinsic motivational factors that motivate an individual to perform work tasks. Conversely, job dissatisfaction can be associated with external motivational factors that are linked to contextual or external factors. The constructs of satisfaction and dissatisfaction have also been explained in relation to intrinsic and extrinsic motivation with regard to academic employment (liacqua, Schumacher \& Li, 1995).

Herzberg (1987) developed the motivation-hygiene theory, one of the most widely used theories consulted in the redesign of work. This theory explains the differences between employee satisfaction, which he also refers to as motivation, and dissatisfaction, as well as those factors in the workplace that cause satisfaction or dissatisfaction. The workplace variables that caused satisfaction presumably motivated employees to perform their work and were thus referred to as motivators, and the factors that caused dissatisfaction were referred to as dissatisfaction-avoidance or hygiene factors. Herzberg (1987) characterized "achievement, recognition, characteristics of the work itself, responsibility, and advancement" (p. 92) as motivators that are associated with job satisfaction. The term "hygiene" refers to factors that have the potential to lead to employee dissatisfaction because if they are present, they only qualify to meet the basic human needs that characterize a normal work environment such as physiological, safety and social demands, which alone are not sufficient to produce employee satisfaction (Zhang \& von Dran, 2000). These factors include "company policy and administration, supervision, interpersonal relationships, working conditions, salary, status and security" (p. 92).

Herzberg (1987) postulates that the factors involved in producing job satisfaction (and motivation) should be differentiated from those factors that lead to job dissatisfaction. Herzberg also claims that because separate and distinct factors should be considered when examining the two constructs, job satisfaction and dissatisfaction are not opposites of each other. Therefore the opposite of job satisfaction is not job dissatisfaction, according to Herzberg, but, rather, no satisfaction and similarly the opposite of job dissatisfaction is no job dissatisfaction. According to Herzberg, two separate and distinct sets of human needs are involved. One set of needs involve the built-in drive to avoid pain from the environment and the learned drives that become conditioned to basic biological needs. Herzberg provides the example of hunger as a basic biological drive, which makes is necessary to earn money, and subsequently money becomes a specific drive.

Herzberg defines the other set of needs as related to the unique human characteristic of the ability to achieve and as a result of this achievement, the individual ability to achieve psychological growth. He further clarifies that the stimuli necessary to meet individual growth needs in the workplace is the job content, and the stimuli necessary to induce pain-avoidance behavior are found in the work environment.

The level of satisfaction is important because it impacts the retention of faculty, especially faculty of color (See Herzog, 2010; Sabharwal \& Corley, 2009; Tack \& Patitu, 1992). Institutions invest so much time and money in recruiting and developing faculty that it behooves them to retain all faculty, especially faculty of color.

\section{Data Source}

\section{METHODOLOGY}

We analyzed data from the National Center for Education Statistics' (NCES) 1999 National Study of Postsecondary Faculty (NSOPF: 99) database. It is the most comprehensive study of 
U.S. faculty in postsecondary educational institutions ever undertaken, with data collected from sampled faculty in a multistage effort (NCES, n.d.). According to NCES, the purpose of collecting NSOPF data was to provide data about faculty to postsecondary education researchers, planners, and policymakers and to understand who faculty are; what they do; and whether, how, and why they are changing. Approximately 28,600 faculty and instructional staff from 960 degree-seeking postsecondary institutions completed the self-reported survey (U.S. Department of Education, 2002).

It is important to understand that utilizing secondary data restricts the researcher to using variables or data originally collected (Herron, 1989) and secondary data is not collected to answer the secondary user's specific research questions (Kozoil \& Arthur, 2011; Crossman, n.d.). The advantages of time and money, breath of data available (Kozoil \& Arthur, 2011; Crossman), and oversampling of certain groups transcends the disadvantages of using secondary data.

\section{VARIABLES AND MEASURES}

Three groups of Asian faculty members were studied in this research project according to their citizenship status and they included (1) U.S. citizens; (2) citizens, foreign born; and (3) noncitizens. The purpose of this study is to better understand Asian faculty members based upon their citizenship status and to evaluate similarities and differences in their satisfaction levels, opinions, and experiences on the college campus. This study will aid in determining if there are differences in Asian faculty perceptions of the campus and academic environment.

For this study, two demographic variables from the 1999 NSOPF database were used - "Asian faculty" and "citizenship types." Asian faculty in the NSOPF database were coded as "Asian" if they responded to the race/ethnicity question that they were Asian or Pacific Islander (NCES). Asian or Pacific Islander faculty responding to self-reported surveys are usually a small sample size, therefore the various Asian groups responding to the NSOPF database were collapsed into one group classified as "Asian." Another variable utilized from the NSOPF database was "citizenship types" and it was coded in the NSOPF database as U.S. citizens, citizens, foreign born or non-citizens (See NCES).

Data for the current study were analyzed using SAS Statistical Tools and Thomas and Heck's (2001) research that is ideal for handling large and complex data such as NSOPF. The margin of error for this study is at the $\mathrm{p}<.05$ level. The research questions that are germane to this study are as follows: 1 ) Are there statistically significant differences in level of satisfaction and experiences of Asian faculty by citizenship status; and 2) Are there statistically significant differences in the opinion and experiences of Asian faculty by citizenship status.

Dependent variables utilized in this study are satisfaction variables and opinion variables. There are 17 satisfaction variables (e.g., satisfaction with undergraduate students, satisfaction with workload, satisfaction with job overall) and the responses were coded as are "1=Very dissatisfied"; "2=Somewhat dissatisfied"; "3=Somewhat satisfied"; "4=Very satisfied." Additionally, there were 12 opinion variables (e.g., opinion about teaching as promotion criteria, opinion of workload increase, opinion of atmosphere for expression of ideas) and the responses were coded as "1=Strongly disagree"; "2=Disagree"; "3=Agree"; "4=Strongly agree" (For a list of the variables see Table 1 and Table 3, respectively).

Data were analyzed using SAS Statistical Tools. Presented in Table 1 are the means and standard deviations of the 17 satisfaction variables studied. Variables were selected from a restricted set of variables. In Table 2, a Multiple Analysis of Variance (MANOVA) was conducted to determine if there were statistically significant differences among the three 
groups of faculty and their perceptions of the satisfaction variables. The tables consist of the sum of squares, the F-values and p-values for the 17 satisfaction variables.

Table 3 displays the means and standard deviations of the 12 opinion variables studied. In Table 4, a Multiple Analysis of Variance (MANOVA) was conducted to determine if there were statistical significant differences among the three groups of faculty and their perceptions regarding the opinion variables. The tables consisted of the sum of squares, the F-values and pvalues for the 12 opinion variables.

\section{FINDINGS}

The purpose of this study is to better understand Asian faculty members based on citizenship status and to evaluate similarities and differences in their satisfaction levels, opinions, and experiences on the college campus. There were a total of 480 Asian faculty members in this study, of which $15 \%$ were U.S. citizens $(n=71) ; 45 \%$ were citizens, foreign born $(n=215)$; and $40 \%$ were non-citizens $(\mathrm{n}=194)$. The majority of the faculty members were married with dependents $(76 \%)$ and male $(72 \%)$. Additionally, the faculty members in this study were tenured $(44 \%)$, on the tenure track $(25 \%)$, not on the tenure track $(25 \%)$, and $5 \%$ were employed at institutions with no tenure system.

There were 17 satisfaction variables studied in this research (See Tables $1 \& 2$ ). On average, Asian faculty members by citizenship status were either "somewhat satisfied" or "somewhat dissatisfied" with the campus environment. Of the 17 satisfaction variables, there were 12 variables in which the faculty were similar in their responses and the remaining five variables they were mixed in their responses. On average, faculty were "somewhat satisfied" in regards to the variables - decide course content, decide course taught, available to advise students, class prep, and job security. Moreover, faculty were "somewhat dissatisfied" in regards to the variables - quality of undergraduate students, workload, time to keep current in the field, effectiveness of faculty leadership, salary, benefits, and spouse employment opportunity. They were mixed in regards to the variables - job decision, quality of graduate students, advancement opportunity, freedom to do consulting, and job overall (See Table 1).

Specifically, the five somewhat satisfied variables were "satisfaction with the authority to decide course content" (Mcitizen = 3.69, Mforeign=3.59, Mnon=3.58); "satisfaction with the authority to decide course taught" (Mcitizen = 3.37, Mforeign=3.24, Mnon=3.17); "satisfaction with time available to advise students" (Mcitizen $=3.09$, Mforeign=3.16, Mnon=3.00); "satisfaction with time available for class preparation" (Mcitizen $=3.09$, Mforeign=3.16, Mnon=3.01); and "satisfaction with job security" (Mcitizen = 3.20, Mforeign=3.37, Mnon=3.01).

The seven variables with which faculty specifically expressed dissatisfaction were satisfaction with quality of undergraduate students (Mcitizen $=2.90$, Mforeign=2.77, Mnon=2.63); satisfaction with workload (Mcitizen $=2.80$, Mforeign=2.85, Mnon=2.85); satisfaction with time to keep current in the field (Mcitizen $=2.58$, Mforeign=2.69, Mnon=2.63); satisfaction with effectiveness of faculty leadership (Mcitizen $=2.49$, Mforeign=2.47, Mnon=2.50); satisfaction with salary (Mcitizen $=2.41$, Mforeign=2.44, Mnon=2.21); satisfaction with benefits (Mcitizen = 2.77, Mforeign=2.80, Mnon=2.60); and satisfaction with spouse employment opportunity (Mcitizen $=2.87$, Mforeign=2.81, Mnon=2.58). The remaining five variables revealed differences in their satisfaction level: satisfaction with authority to make other job decision (Mcitizen $=3.18$, Mforeign=3.01, Mnon=2.93); satisfaction with quality of graduate students (Mcitizen $=2.97$, Mforeign=3.01, Mnon=2.92); satisfaction with advancement opportunity (Mcitizen $=3.09$, Mforeign=2.88, Mnon=2.72); and satisfaction with freedom to do 
consulting(Mcitizen = 3.03, Mforeign=3.13, Mnon=2.96); and job overall(Mcitizen = 3.06, Mforeign=3.06, Mnon=2.95) (See Table 1).

Of the 17 satisfaction variables studied, only four variables were statistically significant. These variables were satisfaction with job security $(\mathrm{F}=7.97, \mathrm{p}=.0004)$; satisfaction with advancement opportunity $(\mathrm{F}=4.46, \mathrm{p}=0.120)$; satisfaction with salary $(\mathrm{F}=3.49, \mathrm{p}=.0314)$ and satisfaction with spouse employment opportunity $(\mathrm{F}=3.69, \mathrm{p}=0.0256)$. The Wilks' Lambda is 0.7559 (76\% of the variance was unaccounted for by the response variable) and Pillai's Trace is significant at .0001 (See Table 2).

In sum, the satisfaction levels of the Asian faculty in this study are mixed. Approximately onehalf of the variables studied revealed faculty are somewhat satisfied in relation to such variables as "decide course content," "time available for class preparation" and "job security," and the remaining variables revealed they are dissatisfied with such variables as "workload," "time to keep current in field" and "salary \& benefits" (See Table 1). On the other hand, onehalf of the variables studied revealed faculty are somewhat dissatisfied in such variables as "satisfaction with workload," "satisfaction with time to keep current in the field" and "satisfaction with benefits."

Another set of variables studied in this research were related to Asian faculty members' opinion about the academic environment. There were 12 opinion variables studied and 10 of them in which the faculty displayed similar opinions (See Tables 3 \& 4). Moreover, there are only two of the opinion variables in which the faculty were mixed in their responses ("disagree" and "agree").

There was only one variable that revealed a statistically significant difference, the opinion that faculty workload had increased (Mcitizen = 3.05, Mforeign=3.08, Mnon=3.10). In relation to this variable, Asian faculty agreed that workload has increased. Nine of the 12 variables revealed that the faculty members disagree regarding the opinion about the opinion variables studied: teaching as promotion criteria (Mcitizen $=2.87$, Mforeign=2.74, Mnon=2.65); research as promotion criteria (Mcitizen $=2.37$, Mforeign=2.72, Mnon=2.91); research rewarded more than teaching (Mcitizen $=2.45$, Mforeign=2.75, Mnon=2.64); post-tenure review of faculty (Mcitizen $=2.91$, Mforeign=2.90, Mnon=2.96); treatment of minority faculty (Mcitizen $=2.77$, Mforeign=2.76, Mnon=2.76); undergraduate education at institution (Mcitizen $=2.55$, Mforeign=2.51, Mnon=2.55); atmosphere for expression of ideas (Mcitizen = 2.37, Mforeign=2.38, Mnon=2.39); quality of research at institution (Mcitizen = 2.27, Mforeign=2.25, Mnon=2.25); and full-time faculty replaced by part-time faculty (Mcitizen $=2.66$, Mforeign=2.44, Mnon=2.48) (See Table 3). There were two variables for which Asian faculty member opinions differed-treatment of female faculty (Mcitizen $=2.90$, Mforeign=3.10, Mnon=3.04) and the ability to obtain funding (Mcitizen $=2.86$, Mforeign=3.05, Mnon=3.10) -but they were not statistically significant.

In sum, the Asian faculty in this study was very dissatisfied with the opportunity to express their opinion about issues (e.g. "opinion about research rewarded more than teaching," "opinion about ability to obtain funding," \& "opinion about undergraduate education at the institution") (See Table 3). Of the 12 opinion variables studied, only one was statistically significant: opinion about research as promotion criteria $(F=11.45, p=.0001)$. The Wilks' Lambda is 0.7559 (76\% of the variance is unaccounted for by the response variable) and Pillai's Trace is significant at .0001 (See Table 4).

Overall, the findings of this study revealed that Asian faculty, regardless of citizenship status, are both "somewhat dissatisfied" and "somewhat satisfied" with their workload, productivity 
and experiences at their particular institution. There are only four variables in which they differ in their views regarding satisfaction at their institution and they are related to finances (job security, advancement opportunities, salary, \& spouse employment opportunity). Additionally, these faculty are very similar, despite their citizenship status, regarding their opinions about what is ensuing at their institution. As a group, they generally "disagree" with the opinions variables in this study when they are provided opportunities to express their opinions about issues related to their institution.

\section{LIMITATIONS}

This study, like other studies utilizing secondary data, has some limitations with regard to the sampling techniques employed. Asian faculty selected in this study were not stratified by institutional type because the sample size for this group was small, which is another limitation of the study. It should be noted that satisfaction levels, opinions, and experiences could possibly be different for the Asian faculty based on their institutional type. Faculty at two-year institutions encounter different experiences than faculty at four-year institutions.

Another limitation of the study is the use of self-reported data. According to Cook and Campbell (1979) as cited by Yu (n.d.), "Subjects (a) tend to report what they believe the researcher expects to see, or (b) report what reflects positively on their own abilities, knowledge, beliefs, or opinions" ( $($ 1). One must also be careful in interpreting and generalizing the results of this study due to the limitations.

\section{DISCUSSION AND IMPLICATIONS}

The role of American higher education has evolved. Higher education will continue to evolve in the future in response to the dynamics of diversity and globalization. The purpose of this study is to better understand the impact of satisfaction and opinions of Asian faculty in U.S. institutions by citizenship type. This research is important because we need to understand the experiences of international scholars in order to best accommodate their needs and retain a diverse faculty. There is a very limited amount of research that focuses on the satisfaction or opinions of Asian faculty. There are a couple of current research studies that focus on foreignborn Asian faculty and Asian American faculty using the NSOPF databases, but there are not any studies that emphasize the three citizenship types discussed in this study. We will attempt to understand and address the similarities and differences among Asian faculty in this study.

The findings of this study revealed that Asian faculty, regardless of citizenship status, are mixed in the level of satisfaction regarding their experiences at their particular institution. The responses by citizenship type revealed that the U.S. citizens and foreign-born citizens were similar in their responses regarding the satisfaction level. Both groups were "somewhat satisfied" in response to nine variables and "somewhat dissatisfied" in response to eight variables. On the other hand, non-citizen Asian faculty were "somewhat dissatisfied" with 12 of the 17 variables.

Moreover, the findings in this study revealed that the non-citizen Asian faculty members were more dissatisfied than the Asian faculty who were U.S. citizens and foreign-born citizens. Moreover, Asian faculty members' opinions were not very positive about the environment in which they work (See Table 3). Asian faculty also appeared to be more similar as a group regarding every variable except for the variable "opinion about research as promotion criteria." These findings were consistent for the three citizenship types that were explored in this study. Interpreting the results of this study raised more questions than providing answers regarding the three groups of faculty according to citizenship status. 
Non-citizen Asian faculty members may have been more dissatisfied than the U.S. citizen and foreign-born Asian faculty groups because according to Bockner (2003), temporary citizens experience a certain degree of culture shock, stress and sociocultural disruption as they attempt to adjust to U.S. culture. Many non-citizen Asian faculty members are not familiar with the academic culture and educational system of the U.S., which tends to be very different than the Asian academic culture. Additionally, the academic culture of postsecondary institutions can be intimidating, and the process of simply teaching courses in the U.S. can promote a certain amount of insecurity and discomfort. This is consistent with a report by Wells, Seifert, Park, Reed, and Umbach (2007) that stated Asian faculty are less satisfied with overall job satisfaction. Skachkova (as cited in Mamiseishvili, 2011) indicated that judgments regarding foreign-born faculty members' teaching effectiveness were associated with their linguistic proficiency.

The findings revealed that foreign-born citizens and non-citizens were similar in their responses to opinion variables when compared to U.S. citizens. They "agreed" on the same three opinion variables and "disagreed" on the same nine opinion variables. U.S. citizens were similar in their responses to the other two groups but differ in the variables related to the treatment of female faculty and the ability to obtain funding.

Asian faculty members may not have very positive opinions about the environments in which they work because as Stanley (2006) discussed, faculty of color experience feelings of isolation and low self-esteem regarding their professional accomplishments. They also experience high levels of work stress and they have to work twice as hard to be treated equal to their counterparts (Hagedorn, 2000). Additionally, Jackson (2004) stated that the problems experienced by some faculty of color included being discouraged and less supported..." (pp. 179-180).

Asian faculty appeared to be more similar as a group regarding every variable except the variable "opinion about research as promotion criteria," and this held true for the three citizenship types under study. The emphasis placed on research as a promotion criteria will vary across institutions depending upon the mission, goals and institutional type, which could explain the lack of consensus among the groups regarding this variable. The reward structure and value assigned to research at a given institution will alter faculty perceptions of these promotion criteria. This faculty group is not necessarily privileged to important information about the campus culture such as criteria for promotion and tenure and the implicit norms that constitute a significant proportion of the process; they are more apt to be uncertain about their future because they are not citizens; and finally, they do not feel they have the same academic freedoms as other colleagues. Moreover, one huge barrier discussed in the literature about non-citizen Asian faculty is the inability to appropriately communicate with colleagues and students.

In this study, Asian faculty were satisfied with the authority to decide course content; courses taught; time available to advise; and time available for class preparation.. These variables, which can be defined as "responsibility for certain aspects of the job," are consistent with Herzberg's (1987) motivation-hygiene theory which describes the motivators associated with job satisfaction as "achievement, recognition, characteristics of the work itself, responsibility, and advancement" (p. 92). There were also several variables related to workload, leadership, salary and benefits with which faculty were dissatisfied, and these variables were consistent with Herzberg's explanation of hygiene factors that have the potential to lead to employee dissatisfaction such as "company policy and administration, supervision, interpersonal relationships, working conditions, salary, status and security" (p. 92). 
There were only four significant variables in this study and they were related to job security, advancement opportunity and salary. According to Herzberg's model, they would be characterized as hygiene variables which could provoke dissatisfaction because they are extrinsic motivators. The constructs of satisfaction and dissatisfaction have been explained in relation to intrinsic and extrinsic motivation with regard to academic employment (liacqua, Schumacher \& Li, 1995).

The authors are not saying that these barriers exist for all non-citizen faculty members but they do exist at an alarming rate. It is assumed that having citizenship in the U.S. can be a form of security for some Asian faculty. It has implied that the hygiene factors in Herzberg's theory lead to dissatisfaction in terms of overall job satisfaction for Asian faculty. In addition, the feeling of being otherness and excluded from the White dominating academy were reported by Asian faculty members in the Wells et al. (2007) study. Apparently, citizenship could reinforce both feelings of job security and non-otherness for non-citizen Asian faculty. Also, critical racial theory might be able to provide a theoretical conceptualization to understand their dissatisfaction in U.S. higher education.

As these different barriers are taken into consideration, what can postsecondary institutions do to obliterate the barriers or provide a more comfortable academic environment, improve satisfaction and provide opportunity to express opinions? Listed below are implications that administrators should consider in order to successfully acculturate Asian faculty members into campus and academic environment of higher education institutions.

1) Institutions do not effectively acculturate new faculty of color into the academic environment. Therefore, administrators should make sure that this faculty group is aware of the established values, beliefs, and assumptions that characterize the academic culture and environment. These components form the basis of reality for organizational participants and are established after faculty undergo the process of interpreting their experiences within the academic environment (Bolman \& Deal, 2008).

2) Research seems to be the major mechanism by which faculty can display their scholarly competency. Higher education institutions clearly need to rethink their reward structures, value systems, and the expectations regarding faculty work in order to keep highly productive faculty more satisfied with their jobs, and thus provide them with the academic workplace that is more appealing and attractive.

3) The role of faculty and the factors that affect their teaching experiences and job satisfaction have progressed and will continue evolve to cope with change (Drysdale, 2005). Research on conditions that influence job satisfaction for faculty will not only contribute to the development of a faculty of excellence but also to the well-being of higher education as a whole (Fife, 2000).

One issue should be considered for future consideration. There are only $24 \%$ of the respondents for this study who are female. It would be interesting to know if the responses would differ if there were more Asian female respondents. Finally, the researchers found that citizenship status contributed very little to the variance of the satisfaction variables and even less in the opinion variables.

\section{References}

Ali, p. (2009). Job satisfaction characteristics of higher education by race. Educational research and review, 4(5), 289-300. 
Baruch, y., budhwar, p. S., \& khatri, n. (2007). Brain drain: inclination to stay abroad after studies. [online]. Journal of world business, 42, 99-112. Retrieved from www.sciencedirect.com.

Bochner, s. (2003). Culture shock due to contact with unfamiliar cultures. Online readings in psychology and culture, unit 8. Retrieved from http://scholarworks.gvsu.edu/orpc/vol8/iss1/7

Bolman, l. G., \& deal, t. E. (2008). Reframing organizations: artistry, choice, and leadership. 4th edition. San francisco, ca: jossey bass

Bronstein, p. (1993). Challenges, rewards, and costs for feminists and minority scholars. In j. Gainen \& r. Boice (eds.), building a diverse faculty (pp. 61-70). San francisco: jossey-bass.

Chan, s. (2005). In defense of asian american studies: the politics of teaching and program building. Urbania: university of illinois press.

Crossman, a. (n.d.). Secondary data analysis. Available at http://sociology.about.com/od/researchmethods/a/secondary-data-analysis.htm

Daly, c.j. \& dee, j.r. (2006, sep. - oct.). Faculty turnover intent in urban public universities. The journal of higher education, 77(5), 776-803

Drysdale, d. S. (2005). Faculty job satisfaction: retaining faculty in the new millennium. Unpublished doctoral dissertation, montana state university, bozeman.

Fife, j. D. (2000). Forward. In tack, martha w. \& patitu, carol l. (eds.). Faculty and job satisfaction: women and minorities in peril, (p. Xviii). School of education and human development, george washington university, washington d. C.

Freeman, r.b. (2006). Does globalization of the scientific/engineering workforce threaten u.s. economic leadership. Retrieved from http://www.nber.org/chapters/c0207.pdf?new_window=1

Fujimoto, m. J. (1996). The community college presidency: an asian pacific american perspective. New directions for community colleges, 94, 47-56.

Hagedorn, linda serra. (2001). Gender differences in faculty productivity, satisfaction, and salary: what really separates us? [washington, d.c.] : distributed by eric

Clearinghouse, retrieved from http://www.eric.ed.gov/contentdelivery/servlet/ericservlet?accno=ed 464548

Herron, d.g. (1989). Secondary data analysis: research method for the cns. Clinical nurse specialist 3(2), 66-69.

Herzberg, f. (1987, september-october). One more time: how do you motivate employees? Harvard business review.

Herzog, nathan b. (2010). Keeping the ones you want: a study of faculty satisfaction and faculty retention in higher education. No. 3391488. Capella university. Ann arbor: proquest. Web.

Hune, s., \& chan, k. (1997). Special focus: asian pacific american demographic and educational trends. In d. Carter \& r. Wilson (eds.), minorities in higher education: fifteenth annualstatus report: 1996-1997 (pp. 39-67, 103-107). Washington, d.c.: american council on education.

Institute of international education. (2009). Open doors. Retrieved from http://www.iie.org/en/research-andpublications/open-doors

Jackson, j. (2004, spring). The story is not in the numbers: academic socialization and diversifying the faculty. Nwsa journal, 16(1), 172-185.

Johnsrud, l.k. \& sadao, k.c. (1998). The common experience of "otherness": ethnic and racial minority faculty. The review of higher education, 21(4). Retrieved from http://muse.jhu.edu/journals/review_of_higher_education/v021/21.4johnsrud.html.

Jung, j. (2012, december ). Faculty research productivity in hong kong across academic discipline. Higher education studies, 2, (4). Doi:10.5539/hes.v2n4p1

Kavas, a. \& kavas, a. (2008, september). An exploratory study of undergraduate college students' perceptions and attitudes toward foreign accented faculty. [online]. College student journal, 879-890.

Koziol, n. \& arthur, n. (2011). An introduction to secondary data analysis. Available at http://r2ed.unl.edu/presentations/2011/rms/120911_koziol/120911_koziol.pdf

Laden, b. V., \& hagedorn, l. S. (2000). Job satisfaction among faculty of color in academe: individual survivors or institutional transformers? New directions for institutional research, 57-66. 
Boyer, P.G. Woodhouse, S., Han, P. (2015). Satisfaction Levels, Opinions, and Experiences of Asian Faculty on Campus: Does Citizenship Status Make A Difference? Advances in Social Sciences Research Journal, 2(2) 101-115.

Lee, s.j. \& kumashiro, k.k. (2005). A report of the status of asian american and pacific islanders in education. Beyond the "model minority" stereotype. Washington, d.c.: national educational association.

Lee, s. M. (2002). Do asian american faculty face a glass ceiling in higher education? American educational research journal, 39(3), 695-724.

Lee, s. S. (2006). Over-represented and de-minoritized: the racialization of asian americans in higher education. Interactions: ucla journal of education and information studies, 2(2), article 4. Retrieved from http://repositories.cdlib.org/gseis/interactions/vol2/iss2/art4.

Lei, j. (1998, april). (op)posing representations: disentangling the model minority and the foreigner. Paper presented at the aera annual meeting, san diego, ca.

Liacqua, j.a., schumacher, p. \& li, h.c. (1995, fall). Factors contributing to job satisfaction in higher education. Education. Retrieved from http://www.findarticles.com

Lin, z., pearce, r., \& wang, w. (2009) imported talents: demographic characteristics, achievement and job satisfaction of foreign born full time faculty in four-year american colleges. Higher education, 57, 703-721. Doi 10.1007/s10734-008-9171-z.

Madhavan, s. M. (2001). The job satisfaction level of chinese- and indian-born engineering faculty at a research i university. Unpublished doctoral dissertation, west virginia

University.

Mamiseishvili, k. (2011). Teaching workload and satisfaction of foreign-born and u.s.-born faculty at four-year postsecondary institutions in the united states. Journal of diversity in higher education, 4(3), 163-174. Doi: $10.1037 / \mathrm{a} 0022354$.

Mamiseishvili, k, \& rosser, v. J. (2009). International and citizen faculty in the united states: an examination of their productivity at research universities. Research in higher education 51 (1), 88-107.

Mamiseishvili, k. \& rosser, v.j. (2011). Examining the relationship between faculty productivity and job satisfaction. Journal of the professoriate, 5(2), 13-33.

Mcgonigle, d., mastrian, k., farcus, n., eggers, r.m., shoop, l. (2007, february 13). Nurturing faculty: an old concept? [online journal]. Academic leadership (2), 1. Retrieved from http://www.academicleadership.org/emprical_research/nurturing_faculty_an_old_concept_printer.shtml

Milem, j. F., chang, m.j. \& antonio, a.l. (2005). Making diversity work on campus: a research-based perspective. Retrieved from http://www.wesleyan.edu/partnerships/mei/files/makingdiiversityworkoncampus.pdf

Nakanishi, d. (1993). Asian pacific americans in higher education: faculty and administrative representation and tenure. In c. Turner, m. Garcia, a. Nora, \& l. Rendon (eds.), racial and ethnic diversity in higher education (pp. 370375). Needham heights, ma: simon \& schuster.

National center for education statistics (n.d.). The national study of postsecondary faculty overview. Retrieved from http://nces.ed.gov/surveys/nsopf/

National center for education statistics (2008). The digest of education statistics 2008. Washington, d.c.: department of education.

Ng., j. C., lee, s. S., \& pak, y. K. (2007). Contesting the model minority and perpetual foreigner stereotypes: a critical review of literature on asian americans in education. [online]. Review of research in education, 31, 95-130. Doi:10.3102/0091732x07300046095

Omi, m. (2008, september 26). Asians americans: the unbearable whiteness of being? The chronicle of higher education. Retrieved from online at http://chronicle.com section: diversity in academe, 55(5), 56.

Pang, b., \& appleton, n. (2004, september). Higher education as an immigration path for chinese students and scholars. The qualitative report, 9(3), 500-527. Retrieved from http://www.nova.edu/ssss/qr/qr9-3/pang.pdf

Ruffins, p. (1997). The fall of the house of tenure: special report. Careers in higher education. Black issues in higher education, $14,18-26$.

Sabharwal, m. \& corley, e. (2009, september). Faculty job satisfaction across gender and discipline. The social science journal, 46 (3), pp. 539-556. Retrieved from http://dx.doi.org.ezproxy.umsl.edu/10.1016/j.soscij.2009.04.015

Saigo, r.h. (2008, september 30). Why there still aren't enough asian-american college presidents. The chronicle of higher education. Retrieved from http://chronicle.com. Section: diversity in academe, 55(5), b60. 
Sax, l. J., hagedorn, l. S., arredondo, m., \& dicrisi, f. A., iii. (2002, aug). Faculty research productivity: exploring the role of gender and family-related factors. Research in higher education, 43(4), pp. 423-46.

Sieu, m. (1990). Migration and adaptation. A study of asian-born academics in an american university. Unpublished doctoral dissertation, university of california at los angeles.

Smith, e., \& witt, s. L. (1996). A comparative study of occupational stress among african, american and white university faculty: a research note. In c. Turner, m. Garcia, a. Nora, \& l. Rendon (eds.), racial and ethnic diversity in higher education (pp. 381-389). Needham heights, ma: simon \& schuster.

Stanley, c. A. (2006). Coloring the academic landscape: faculty of color breaking the silence in predominantly white colleges and universalities. American educational research journal, 43(4), 701-736.

Suzuki, b. (2002). Revisiting the model minority stereotype: implications for student affairs practice and higher education. In m. Mcewan, c. Kodama, a. Alvarez, s. Lee, \& c. Liang (eds.), working with asian american college students: new directions for student services (vol. 97, pp. 21-32). San francisco: jossey-bass.

Tack, m. W. \& patitu, c. L. (1992). Faculty job satisfaction: women and minorities in peril. Ashe-eric higher education report no. 4. Washington, dc: association for the study of higher education.

Thomas, s. L. \& heck, r. H. (2001). Analysis of large-scale secondary data in higher education research: potential perils associated with complex sampling designs. Research in higher education, 42(5), 517-537.

Tuan, m. (1998). Forever foreigners or honorary whites? The asian ethnic experience today. New brunswick, nj: rutgers university press.

Turner, c. (2002). Women of color in academe. Journal of higher education, 73, 74-93.

U. S. Census bureau. (2002). A profile of the nation's foreign-born population from asia. Retrieved from http://www.census.gov/prod/2002pubs/cenbr01-3.pdf.

U. S. Census bureau. (2005). American community survey change profile 2001-2002. Retrieved from http://www.census.gov/acs/www/products/profiles/chg/2002/0102/tabular/010/01000us1.htm

U.s. census bureau. (2007). The american community asians: 2004. Retrieved from

http://www.census.gov/prod/2007pubs/acs-05.pdf

U. S. Department of education, national center for education statistics. 1999 national study of postsecondary faculty (nsopf:99) methodology report, nces 2002-154, by sameer y. Abraham, darby miller steiger, margrethe montgomery, brian d. Kuhr, roger tourangeau, bob montgomery, and manas chattopadhyay. Project officer: linda j. Zimbler. Washington, dc:2002. Retrieved from http://nces.ed.gov/pubs2002/2002154.pdf

U.s. department of education, national center for education statistics, integrated postsecondary education data system (ipeds), winter 2011-12, human resources component, fall staff section.

Walters, n.p. \& trevelyan, e.n. (2011, november). The newly arrived foreign-born population of the united states: 2010. Retrieved from http://www.census.gov/prod/2011pubs/acsbr10-16.pdf

Wells, r., seifert, t., park, s., reed, e., \& umbach, p. D. (2007). Job satisfaction of international faculty in u.s. higher education. Journal of the performance, 2, 5-32.

Yu, c. (n.d.) Reliability of self-reported data. Retrieved from http://www.creativewisdom.com/teaching/wbi/memory.shtml

Zhang, p. \& von dran, g. M. (2001). Satisfiers and dissatisfiers: a two-factor model for website design and evaluation. Journal of the american society for information science, 51(14), 1253-1268. 
Boyer, P.G. Woodhouse, S., Han, P. (2015). Satisfaction Levels, Opinions, and Experiences of Asian Faculty on Campus: Does Citizenship Status Make A Difference? Advances in Social Sciences Research Journal, 2(2) 101-115.

\section{Table 1 Means and Standard Deviations of Satisfaction Variables for Asian Faculty by Citizenship Status}

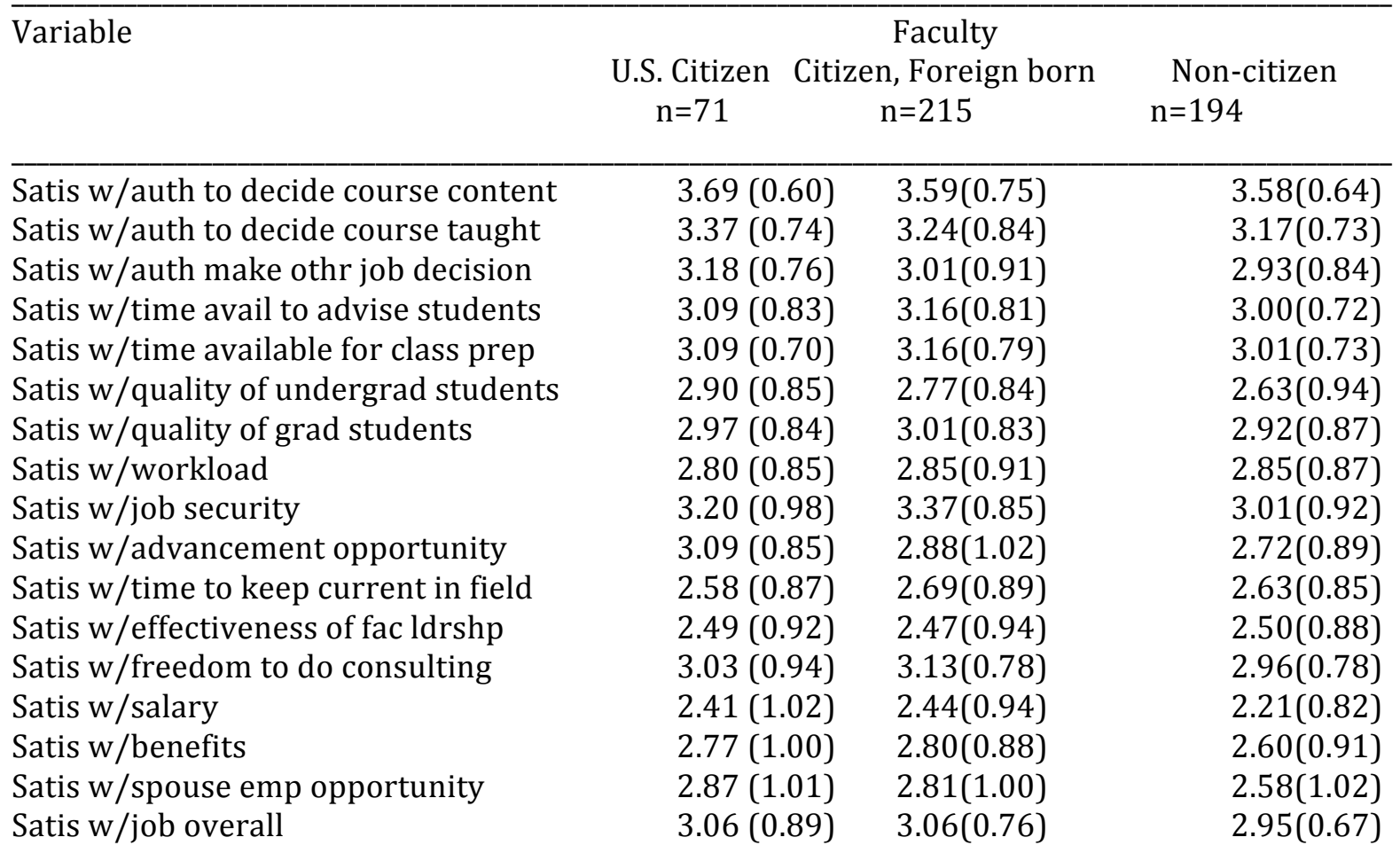

Source: National Center for Statistics, 1999 National Study of Postsecondary Faculty

Note: Possible responses are " $1=$ Very dissatisfied";" $2=$ somewhat dissatisfied"; " $3=$ somewhat satisfied"; "4=Very satisfied"

Table 2 MANOVA for Satisfaction Variables of Asian Faculty by Citizenship Status

\begin{tabular}{|c|c|c|c|}
\hline Variable & & & F-value \\
\hline Satis w/auth to decide course content & 0.716 & 0.75 & 0.4711 \\
\hline Satis w/auth to decide course taught & 2.024 & 1.65 & 0.1934 \\
\hline Satis w/auth make othr job decision & 3.292 & 2.21 & 0.1104 \\
\hline Satis w/time avail to advise students & 2.564 & 2.12 & 0.1215 \\
\hline Satis w/time available for class prep & 2.235 & 1.94 & 0.1449 \\
\hline Satis w/quality of undergrad students & 4.446 & 2.84 & 0.0595 \\
\hline Satis w/quality of grad students & 0.849 & 0.59 & 0.5540 \\
\hline Satis w/workload & 0.156 & 0.10 & 0.9058 \\
\hline Satis w/job security & 12.972 & 7.97 & $0.0004^{* * *}$ \\
\hline Satis w/advancement opportunity & 8.018 & 4.46 & $0.0120^{*}$ \\
\hline Satis w/time to keep current in field & 0.819 & 0.53 & 0.5869 \\
\hline Satis w/effectiveness of fac ldrshp & 0.097 & 0.06 & 0.9431 \\
\hline Satis w/freedom to do consulting & 3.020 & 2.31 & 0.1003 \\
\hline Satis w/salary & 5.768 & 3.49 & $0.0314^{*}$ \\
\hline Satis w/benefits & 4.403 & 2.63 & 0.0728 \\
\hline Satis w/spouse emp opportunity & 7.490 & 3.69 & $0.0256^{*}$ \\
\hline Satis w/job overall & 1.386 & 1.25 & 0.2888 \\
\hline
\end{tabular}

Source: National Center for Statistics, 1999 National Study of Postsecondary Faculty $\mathrm{df}=(2,477)$, Wilks' Lambda $=0.7559$; Pillai's Trace $=.0001$

Note. $p<.05^{*} ; p \leq .01^{* *} ; p \leq .001^{* * *}$. 


\section{Table 3 Means and Standard Deviations of Opinion Variables for Asian} Faculty by Citizenship Status

Variable

\section{Faculty}

U.S. Citizen
$\mathrm{n}=71$ $n=71$
Citizen, Foreign born $\mathrm{n}=215$
Non-citizen $\mathrm{n}=194$

Opin abt teaching as promotion criteria

$2.87(1.03)$

$2.74(0.90)$

$2.65(0.83)$

Opin abt research as promotion criteria

$2.37(0.86)$

$2.72(0.87)$

$2.91(0.78)$

$2.45(0.93)$

$2.75(0.95)$

$2.64(0.88)$

$2.91(0.75)$

$2.90(0.81)$

$2.96(0.73)$

$2.90(0.76)$

$3.10(0.75)$

$3.04(0.69)$

$2.77(0.76)$

$2.76(0.76)$

$2.76(0.72)$

$2.86(0.85)$

$3.05(0.68)$

$3.10(0.69)$

$3.05(0.79)$

$3.08(0.74)$

$3.10(0.66)$

$2.55(0.73)$

$2.51(0.85)$

$2.55(0.83)$

$2.37(0.74)$

$2.38(0.77)$

$2.39(0.70)$

$2.27(0.61)$

$2.25(0.74)$

$2.25(0.65)$

$2.66(0.92)$

$2.44(0.82)$

Source: National Center for Statistics, 1999 National Study of Postsecondary Faculty

Note: Possible responses are "1=strongly disagree";" $2=$ Disagree"; " $3=$ Agree"; "4=strongly agree"

Table 4 MANOVA for Opinion Variables of Asian Faculty by Citizenship Status

\begin{tabular}{llll}
\hline Variable & SS & F-value & p-value \\
\hline Opin abt teaching as promotion criteria & 2.57 & 1.61 & 0.2001 \\
Opin abt research as promotion criteria & 16.03 & 11.45 & $0.0001^{* * *}$ \\
Opin abt resrch reward more than teaching & 4.85 & 2.86 & 0.0582 \\
Opin abt post-tenure review of faculty & 0.46 & 0.39 & 0.6805 \\
Opin abt treatment of female faculty & 2.17 & 2.04 & 0.1313 \\
Opin abt treatment of minority faculty & 0.02 & 0.007 & 0.9870 \\
Opin abt ability to obtain funding & 2.98 & 2.93 & 0.0544 \\
Opin of fac workload increase & 0.12 & 0.13 & 0.8819 \\
Opin of undergrad Ed at institution & 0.14 & 0.10 & 0.9005 \\
Opin of atmosphere for expression of ideas & 0.04 & 0.04 & 0.9622 \\
Opin of qual of research at inst & 0.01 & 0.01 & 0.9877 \\
Opin of F/T fac replaced by P/T faculty & 2.60 & 1.80 & 0.1699
\end{tabular}

Source: National Center for Statistics, 1999 National Study of Postsecondary Faculty $\mathrm{DF}=(2,477)$, Wilks' Lambda $=0.7559$; Pillai's Trace $=.0001$

Note. $P<.05^{*} ; \mathrm{p} \leq .01^{* *} ; p \leq .001^{* * *}$. 